Proceedings

\title{
Repeated Loading of Cement Composite Sandwich Beams ${ }^{+}$
}

\author{
Matthias De Munck ${ }^{1, *}$, Jolien Vervloet ${ }^{1}$, Michael El Kadi ${ }^{1}$, Svetlana Verbruggen ${ }^{1}$, \\ Jan Wastiels ${ }^{1}$, Tine Tysmans ${ }^{1}$ and Olivier Remy ${ }^{2}$ \\ 1 Department Mechanics of Materials and Constructions, Vrije Universiteit Brussel Pleinlaan 2, 1050 Brussel, \\ Belgium; Jolien.Vervloet@vub.be (J.V.); Michael.El.Kadi@vub.be (M.E.K.); \\ Svetlana.Verbruggen@vub.be (S.V.); Jan.Wastiels@vub.be (J.W.); Tine.Tysmans@vub.be (T.T.) \\ 2 CRH Structural Concrete, Marnixdreef 5, 2500 Lier, Belgium; O.Remy@plakagroup.be \\ * Correspondence: Matthias.De.Munck@vub.be; Tel.: +32-2-629-2927 \\ + Presented at the 18th International Conference on Experimental Mechanics (ICEM18), Brussels, Belgium, \\ 1-5 July 2018.
}

Published: 14 June 2018

\begin{abstract}
Using large lightweight prefabricated sandwich panels offers great possibilities for the renovation of existing dwellings. By facilitating the installation process it reduces the total renovation time to a couple of days. During their life-time, these panels will be subjected to wind loading, equivalent to a repeated loading. The effect of this loading condition on the structural behavior of the sandwich panels was verified experimentally. Four-point bending tests were conducted, both static and cyclic. Results showed that the subjection to different loading-unloading cycles resulted in a residual deformation and a decreased stiffness. After being subjected to a repeated loading, the residual ultimate capacity was lowered with $30 \%$.
\end{abstract}

Keywords: sandwich panel; renovation; composite materials; repeated loading

\section{Introduction}

The increasing energy and insulation regulations created a strong need for insulating building solutions. Both for new buildings and for renovations the insulation thickness needs to be increased substantially to meet these regulations. For renovation, the current systems lack the possibility of prefabrication, which inherently leads to a longer renovation time. Ideally this renovation time needs to be reduced to the minimum to limit the inconvenience for the current residents. Using large lightweight prefabricated sandwich wall panels will greatly facilitate the installation process. Placing panels with the height of one floor in front of an existing dwelling will reduce the total renovation time to a couple of days. The panels are attached to the existing structure by means of anchors on discrete locations. Sandwich panels consist of two stiff faces, interconnected by a low stiffness insulating core. Due to their composite action they are characterized by a great stiffness to weight ratio. The presence of the thick insulating core leads to an increase of the insulation value and thus to a better energy performance of dwellings.

Precast concrete sandwich panels are commonly used in construction for industrial buildings. The structural capacity of these panels is guaranteed by steel reinforced concrete faces with a thickness of about $60 \mathrm{~mm}$. To reduce this thickness and inherently the total weight of the panels, cementitious composites offer great possibilities. By replacing the steel rebars by technical textiles the concrete cover can be omitted since textiles are less vulnerable to corrosion. Doing so, lightweight sandwich panels with faces of only a few millimeters thick are created. The feasibility of using cementitious composites to fabricate sandwich elements was already demonstrated by several authors [1-4]. 
During their lifetime facade panels are subjected to varying weathering conditions such as wind, rain, freeze, snow, etc. These environmental conditions induce different kinds of loading conditions within the panels themselves. The subjection to wind can be simulated by a repeated loading. Up to now, very few work has been performed on the fatigue of sandwich panels cladded with textile reinforced cementitious composites. To the author's knowledge only Cuypers et al. studied the behavior of sandwich panels with E-glass fibre reinforced cementitious faces [5]. Focus of her research was put on the residual deformations after small overloads. The background of the fatigue behavior of the cementitious composite material itself is also very limited. Little work was done on the cyclic behavior, where the number of loading cycles was limited to $100[6,7]$.

To gain insight in the fatigue behavior, this paper investigated experimentally the bending behavior of sandwich beams subjected to static and cyclic loading. Eight sandwich beams with a length of $2.50 \mathrm{~m}$ were fabricated. Five of them, the reference samples, were tested by means of a static four-point bending test up to failure. The three other beams were subjected to repeated loading, at different loading levels. One beam was subjected to 100.000 cycles up to $20 \%$ of its ultimate bending capacity (determined form the static tests). Afterwards its residual strength was determined by a static test and compared to the reference beams. The two other beams were subjected to 10.000 cycles up to respectively $30 \%$ and $40 \%$ of the ultimate strength. Conclusions were drawn on the residual deformations and on the stiffness' evolution.

\section{Material Properties}

\subsection{Expanded Polystyrene (EPS)}

For the materialization of the insulating core of the sandwich beams Expanded Polystyrene (EPS) was chosen. The mechanical properties of EPS were less performant compared to other insulating materials, but this was largely compensated by their low density $\left(1520-\mathrm{kg} / \mathrm{m}^{3}\right)$ and low cost. The properties of the used EPS 200 were listed in Table 1.

Table 1. Properties of EPS 200 [8].

\begin{tabular}{cc}
\hline Density $\left(\mathbf{k g} / \mathbf{m}^{3}\right)$ & E-Modulus (MPa) \\
\hline 20 & 10 \\
\hline
\end{tabular}

\subsection{Textile Reinforced Concrete (TRC)}

In order to gain sufficient structural capacity, the insulating core was cladded with Textile Reinforced Cementitious Composites (TRCs). A TRC was composed of a cementitious matrix reinforced with a technical textile. To reduce the total cost of the sandwich panels, a low-cost commercially available AR-glass fibre grid [9] was chosen. The fibres were woven into an orthogonal mesh with a mesh opening of $6 \mathrm{~mm}$ in both directions. The grid had a surface weight of $220 \mathrm{~g} / \mathrm{m}^{2}$ and a nominal tensile strength of $2500 \mathrm{~N}$ per $50 \mathrm{~mm}$.

This textile was embedded in a Portland cement based, shrinkage-compensated mortar with a maximum grain size of $0.5 \mathrm{~mm}$. Only water needed to be added to the mortar. After $5 \mathrm{~min}$ of mixing it stayed workable for about $1 \mathrm{~h}$. The main mechanical characteristics were identified following to the European Standards (EN 196-1:2016) [10]. Six flexural and twelve compression tests were done to determine the flexural strength $\mathrm{f}_{\mathrm{ct}, \mathrm{f}}$ and compressive strength $\mathrm{f}_{\mathrm{cc}}$ of the pure mortar material (Table 2 ).

Table 2. Structural properties of the used mortar.

\begin{tabular}{ccc}
\hline & $\mathbf{f}_{\mathrm{ct}, \mathrm{f}} \mathbf{( M P a )}$ & $\mathbf{f}_{\mathbf{c c}}(\mathbf{M P a})$ \\
\hline Average & 4.96 & 29.60 \\
Standard Deviation & 0.56 & 4.49 \\
\hline
\end{tabular}

Five uniaxial tensile tests were performed to characterize the tensile behavior of the resulting TRC. Aluminum end plates were glued on the TRC specimen with a two-component epoxy glue. To 
gradually reduce the stress concentrations at the transition between the aluminum and the specimen, the end plates were flattened (Figure 1a). The tensile force was applied via a bolt trough the aluminum plates.

In total five specimens were tested. The average stress-strain curve was plotted in Figure 1b. The shaded area represented the standard deviation on the results. The error was small, indicating that the tensile behavior was well captured by the used test set-up. An initial E-modulus of $11.04 \mathrm{GPa}$ was measured and the first cracking stress equaled 1.80 MPa. All specimens failed by tensile rupture of the fibres.

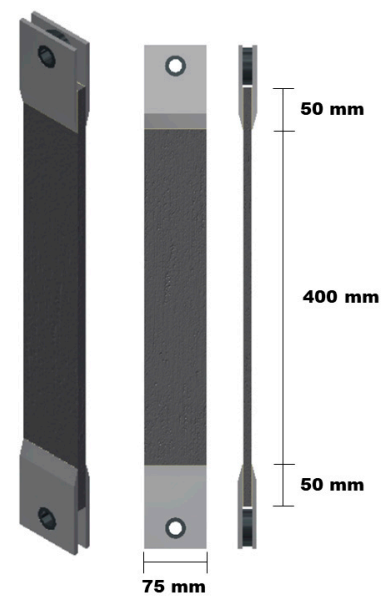

(a)

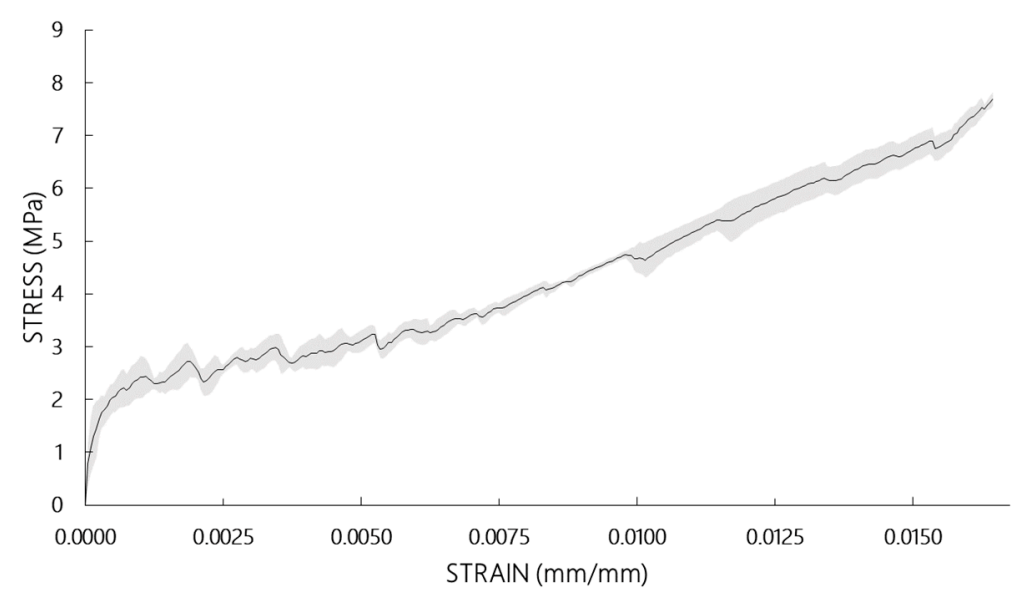

(b)

Figure 1. (a) Aluminum plates were glued to the specimens (b) Average stress-strain curve of the uniaxial tests, the standard deviation is represented by the shaded area.

\section{Experimental Program}

In total eight sandwich beams, with a total length of $2.50 \mathrm{~m}$ and a width of $20 \mathrm{~cm}$ were fabricated and tested. The beams were composed of a $200 \mathrm{~mm}$ thick EPS core on which TRC layers, with a thickness of $5 \mathrm{~mm}$ each were applied. A hand lay-up technique was used for fabrication of the faces. First a layer of mortar was spread out on one side of the EPS core. In this mortar layer a textile grid was embedded. To prevent early evaporation of water, the face was sealed with a plastic cover. After one day of hardening, the other face of the beam was fabricated in the same way. All beams were stored at ambient temperature (approximately $20^{\circ} \mathrm{C}$ ) and a relative humidity between $45 \%$ and $60 \%$ for at least 28 days.

Prior to the cyclic behavior, the static behavior was extensively studied by performing five static bending tests. Subsequently, the fatigue behavior was identified at three different loading stages. One beam was subjected to 100.000 cycles, altering the applied load between $6 \%$ and $20 \%$ of the ultimate capacity of the sandwich beams, which was deduced from the static tests. Afterwards the residual strength was determined by performing a static bending test. The two other beams were subjected to 10.000 cycles at loading levels between $10 \%$ and $30 \%$ and between $10 \%$ and $40 \%$ of the ultimate bearing capacity.

All tests, both static and fatigue, were performed using the same test set-up, namely a four-point bending test (Figure 2). Placed on roller supports, the beams were loaded using a servo-hydraulic actuator with a capacity of $500 \mathrm{kN}$, with a $10 \mathrm{kN}$ loadcell in between. Local stress concentrations were avoided by using distribution plates at the supports and the loading areas. The static tests were displacement controlled with a rate of $1 \mathrm{~mm} / \mathrm{min}$. The cyclic loading was load controlled at a frequency of $0.4 \mathrm{~Hz}$. Displacements were measured in the middle of the beam using a Linear Variable Differential Transducer (LVDT). 


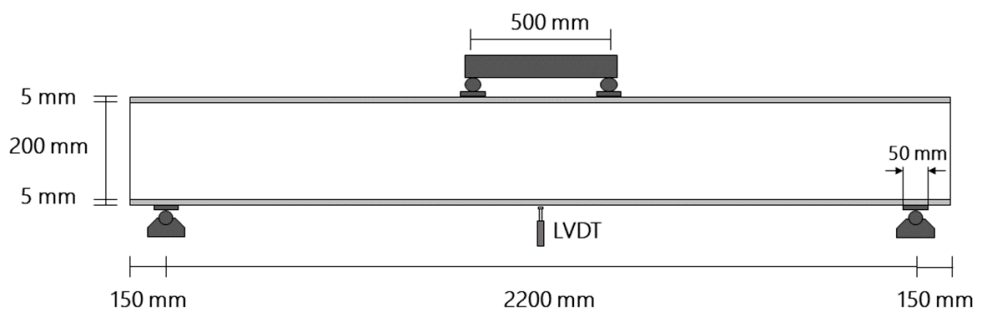

(b)

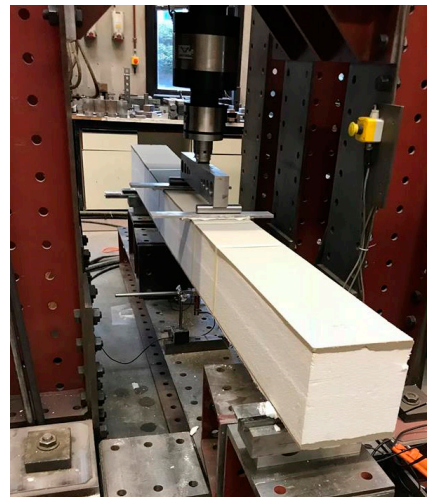

(c)

Figure 2. Four-point bending test: (a) schematic overview; (b) lab set-up.

\section{Results}

From the different static tests the average curve was calculated (Figure 3), the shaded area represents the standard deviation. The sandwich beams are typified by a non-linear behavior, directly coming from the characteristic non-linear tensile behavior of the TRC faces (Figure 1). Until the occurrence of a crack in the lower face, the sandwich specimens exhibited a linear behavior. The formation of cracks led to a loss in stiffness of $71 \%$. The stiffness in the last branch was directly proportional to the amount of textile reinforcement. In all experiments, beam failure was initiated by tensile rupture of the textile. An average maximum load of $4.8 \mathrm{kN}$ was observed.

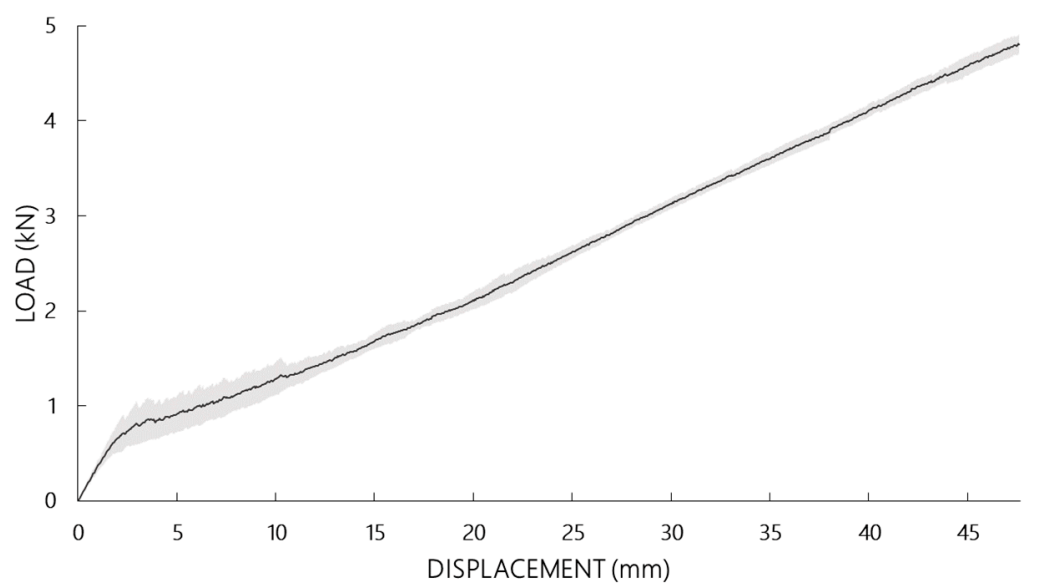

Figure 3. Average load-displacement curve of the static four-point bending tests.

The beams subjected to cyclic loading showed qualitatively similar load-displacement curves. A typical representative hysteresis curve of the bending cyclic loading tests performed in this study was shown in Figure 4a (100.000 cycles between 6 and 20\%). Immediately one can see that a residual displacement was present after the application of a loading/unloading cycle and that it increased with an increasing number of cycles. Additionally, the stiffness of the sandwich beams decreased during the test. A closer study on these two observations was made.

The first beam was subjected to 100.000 loading/unloading cycles between $6 \%$ and $20 \%$ of the ultimate bearing capacity. The stiffness was calculated as the slope of each ascending loading/unloading step in the load-displacement curve. A descending evolution of the stiffness in function of the number of cycles $(\mathrm{N})$ was observed (Figure $4 \mathrm{~b})$. The decrease was the largest during the first cycles. After 10.000 cycles the evolution of the stiffness was more stabilized. 


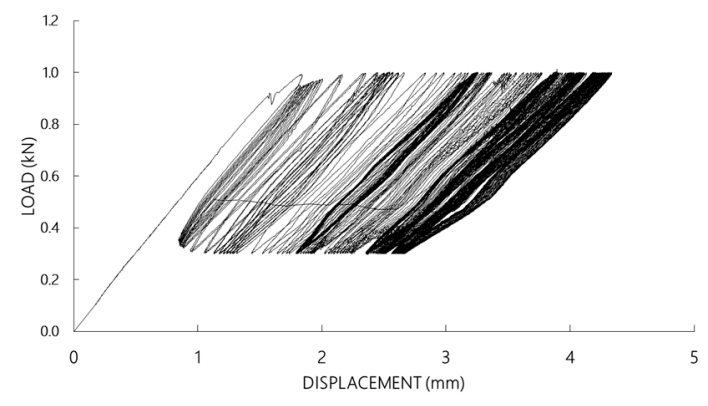

(a)

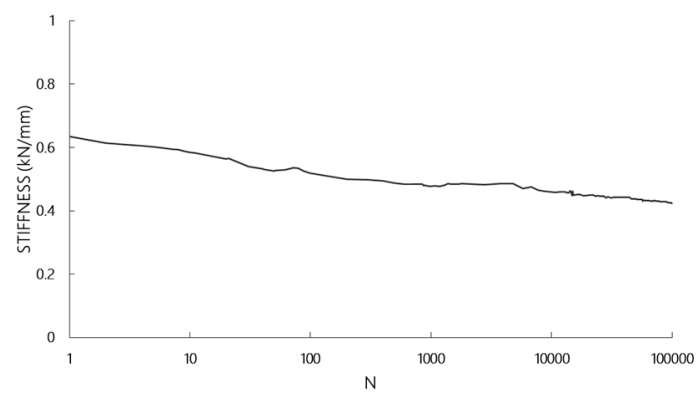

(b)

Figure 4. (a) Typical load-displacement curve of sandwich beams subjected to fatigue loading; (b) Evolution of the stiffness in function of the number of applied loading cycles, varying between $6 \%$ and $20 \%$ of the ultimate bearing capacity.

As the beam didn't reach failure after subjection to 100.000 cycles, a static test was performed to determine its residual strength. Comparison with the results of the initial static tests shows that both the initial stiffness and the ultimate bending capacity were affected by the fatigue loading. The initial stiffness was reduced by $60 \%$, which was a direct result of the formation of cracks during the different loading/unloading steps. The beam failed at a load which was $30 \%$ lower compared to the reference specimens. A possible explanation for this was the residual deformation and accumulated damage (i.e., cracks) in the beam after the cyclic loading.

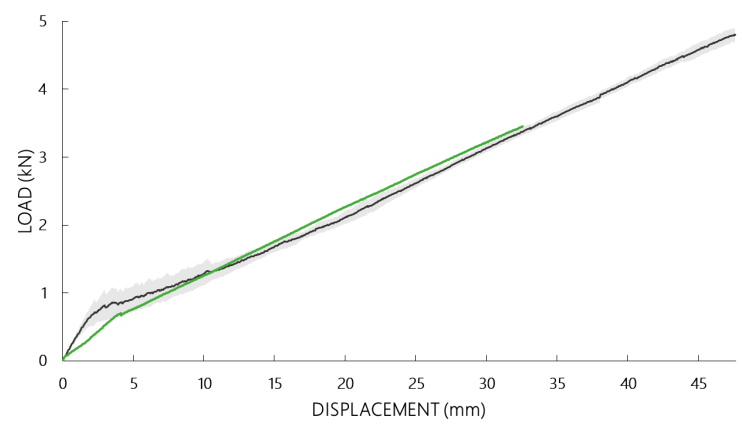

Figure 5. The residual strength after subjection to fatigue loading was identified by a static test and compared to the initial static bending behavior.

The two other beams were subjected to 10.000 cycles at higher loading levels, between $10 \%$ and $30 \%$ and between $10 \%$ and $40 \%$ of the ultimate bearing capacity. The evolution of the minimum and maximum displacement after each loading/unloading cycle was registered (Figure 6). As one can observe, the residual displacements increased as more cycles were applied. The trend for the accumulation of this residual displacement was the same for all loading levels.

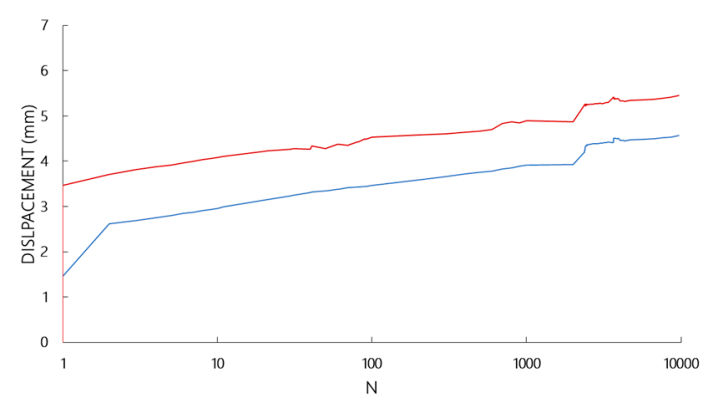

(a)

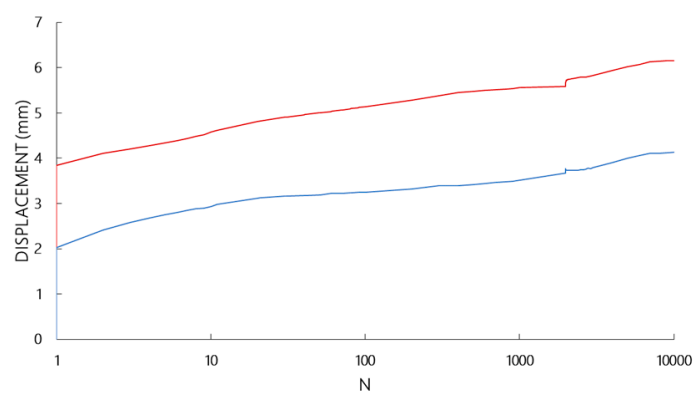

(b)

Figure 6. Evolution of the mid-span displacement in function of the number of cycles N: (a) beam loaded between $10 \%$ and $30 \%$ of the ultimate strength; (b) beam loaded between $10 \%$ and $40 \%$ of the ultimate strength. 


\section{Conclusions}

The authors proposed to use large prefabricated TRC sandwich panels for the renovation of existing dwellings. To check the feasibility of using these panels for construction their behavior on the long-term needed to be verified. Four-point bending tests were performed, both the static behavior and the fatigue/cyclic behavior were quantified.

From the static tests one can conclude that the bending behavior of the sandwich panels was governed by the tensile behavior of the TRC faces. The formation of cracks in the lower tensed face resulted in a loss of stiffness. The beams failed by tensile rupture of the reinforcing textile.

The cyclic loading tests pointed out that the stiffness of the beams decreased after multiple loading/unloading cycles. The loss of stiffness was the most in the first cycles, after 10.000 cycles the decrease was more stabilized. A residual deformation was observed during the repeated loading tests; the more cycles performed, the larger the deformation. Comparison of the residual strength with the reference specimens showed that the ultimate capacity was lowered.

This study gave some first indications of the fatigue behavior of sandwich panels with TRC faces, more research and experiments are necessary to confirm these findings and to identify the different underlying damage mechanisms.

Author Contributions: M.D.M. and S.V. conceived, designed and performed the experiments; M.D.M. analyzed the data and wrote the paper; J.V., M.E.K., J.W., T.T. and O.R. did a first review of the paper.

Acknowledgments: The authors gratefully acknowledge Agentschap voor Innovatie en Ondernemen (VLAIO) and CRH Structural Concrete Belgium nv for funding the research of the first author through a Baekeland mandate.

Conflicts of Interest: The authors declare no conflict of interest.

\section{References}

1. Shams, A.; Stark, A.; Hoogen, F.; Hegger, J.; Schneider, H. Innovative sandwich structures made of high performance concrete and foamed polyurethane. Compos. Struct. 2015, 121, 271-279.

2. Cuypers, H.; Wastiels, J. nalysis and verification of the performance of sandwich panels with textile reinforced concrete faces. J. Sandw. Struct. Mater. 2011, 13, 589-603.

3. Junes, A.; Larbi, A.S. "An experimental and theoretical study of sandwich panels with TRC facings: Use of metallic connectors and TRC stiffeners. Eng. Struct. 2016, 113, 174-185.

4. Colombo, I.G.; Colombo, M.; Prisco, M. Multilayer Precast Facade Panel: structural optimization for the energy retrofitting and for sustainable constructions. In Proceedings of the 10th fib International $\mathrm{PhD}$ Symposium in Civil Engineering, Québec, QC, Canada, 21-23 July 2014.

5. Cuypers, H.; Gu, J.; Croes, K.; Dumortier, S.; Wastiels, J. Evaluation of fatigue and durability properties of E-glass fibre reinforced phosphate cementitious composite. In Proceedings of Brittle Matrix Composites 6, Warsaw, Poland, 9-11 October 2000.

6. Mesticou, Z.; Bui, L.; Junes, A.; Larbi, A.S. Experimental investigation of tensile fatigue behaviour of Textile-Reinforced Concrete (TRC): Effect of fatigue load and strain rate. Compos. Struct. 2017, 160, 1136-1146.

7. Hegger, J.; Voss, S. Investigations on the bearing behaviour and application potential of textile reinforced concrete. Eng. Struct. 2008, 30, 2050-2056.

8. Kemisol, “Technische Documentatie EPS,” 2004. Available online: http://www.kemisol.be/ (accessed on 15 March 2018).

9. Knauf, "Gitex, Glasvezelwapening Technische Fiche." Available online: http://www.knauf.be/nl/product/gitex-glasvezelwapening (accessed on 18 January 2018).

10. Belgisch Instituut Voor Normalisatie (BIN). NBN EN 196-1:2016 Methods of Testing Cement-Part 1: Determination of Strength. 2016. Available online: https://www.nbn.be/nl/catalogue/standard/nbn-en-196-1-1 (accessed on 15 March 2018).

(C) 2018 by the authors. Licensee MDPI, Basel, Switzerland. This article is an open access article distributed under the terms and conditions of the Creative Commons Attribution (CC BY) license (http://creativecommons.org/licenses/by/4.0/). 